\title{
EXTRACAPSULAR TOTAL THYROIDECTOMY IN THE BENIGN THYROID DISEASE
}

\author{
Daniela Sala ${ }^{凶}$, R. Neagoe \\ Second Department of Surgery, Emergency Mureș County Hospital, \\ University of Medicine and Pharmacy Târgu Mureș
}

\begin{abstract}
EXTRACAPSULAR TOTAL THYROIDECTOMY IN THE BENIGN THYROID DISEASE (Abstract): The extracapsular total thyroidectomy is the surgical technique for the monobloc resection of the thyroid parenchyma, between the Charpy fascia and the thyroid gland's own capsule with the preservation of the recurrent nerve, parathyroids, and the exterior branch of the superior laryngeal nerve. Even though this technique represents the treatment of choice in the case of malignant thyroid lesions (in association with the lateral or central compartment lymphadenectomy or not), its indication has been extended in the presence of a benign cytology (FNAB - Bethesda II, III) associated with lesions disseminated in the entire thyroid parenchyma. The intracapsular total thyroidectomy, the subtotal thyroidectomy and the Dunhill operation are surgical techniques also indicated in the case of benign multinodular thyroid lesions disseminated in the entire parenchyma. The aim of this video documentary is to illustrate the extracapsular total thyroidectomy in the benign thyroid disease. Different procedures key points are highlighted: operating room set up, the regional bilateral superficial cervical plexus anaesthesia with the aim of reducing post-operatory pain, the left lateral surgical approach of the left thyroid lobe, and the superior polar approach of the right thyroid lobe respectively, the extracapsular monobloc resection of the thyroid parenchyma spearing the recurrent nerve and the parathyroids, the dissection of the James-Berry ligament, drainage and closure of the musculofascial plans and the wound. Even the indication of extracapsular total thyroidectomy in the case of benign thyroid lesions is still controversial, this technique reduces the risk of recurrent and parathyroid complications and, the risk to develop tumors on the remnant thyroid parenchyma.
\end{abstract}

KEY WORDS: THYROID; BENIGN NODULAR LESION; EXTRACAPSULAR TOTAL THYROIDECTOMY; JAMES-BERRY LIGAMENT

SHORT TITLE: Extracapsular total thyroidectomy

HOW TO CITE: Sala D, Neagoe R. [Extracapsular total thyroidectomy in the benign thyroid disease] Jurnalul de chirurgie (Iaşi). 2013; 9(4): 359. DOI: 10.7438/1584-9341-9-4-10.

Video

Received date: 29.08 .2013

Accepted date: 20.09 .2013

Correspondence to: Daniela Sala MD, PhD

Second Surgical Clinic, Emergency County Hospital Mureș

Str. Gh. Marinescu, no. 50, 540136

Târgu Mureş, Romania

Tel.: $0040(0) 265212111$

Fax: 0040 (0) 265215768

E-mail: salatatiana@yahoo.com 
